\title{
Histopathological analysis of corticosteroid- antibiotic preparation and propolis paste formulation as intracanal medication after pulpectomy: an in vivo study
}

\author{
Isabela França de Almeida Santos RAMOS ${ }^{1}$, Michelle Tillmann BIZ², Niraldo PAULINO³ ${ }^{3}$ Amarilis SCREMIN ${ }^{4}$, Álvaro
} DELLA BONA ${ }^{5}$, Fernando Branco BARLETTA ${ }^{6}$, José Antônio Poli de FIGUEIREDO ${ }^{7}$

\footnotetext{
1- MSc, Department of Biology and Health Science, University of Planalto Catarinense, SC, Brazil.

2- PhD, Adjunct Professor, Morphology Science Department, Federal University of Santa Catarina, Florianópolis, SC, Brazil.

3-PhD, Biomedication Research and Development Group, Professional Masters Program in Pharmacy, Bandeirante University of São Paulo, São Paulo, SP, Brazil.

4- MSc, Department of Pharmacy, Barriga Verde University Center, Florianópolis, SC, Brazil.

5- PhD, Senior Professor and Postgraduate Program, Dental School, University of Passo Fundo, Passo Fundo, RS, Brazil.

6- PhD, Professor Postgraduate Program, Lutheran University of Brazil; Adjunct Professor, University of Santa Cruz do Sul, Santa Cruz do Sul, RS, Brazil.

7- PhD, Coordinator of the Postgraduate Program in Dentistry, Pontifical Catholic University of Rio Grande do Sul, Porto Alegre, RS, Brazil.
}

Corresponding address: Prof. Michelle Tillmann Biz - Campus Universitário Reitor João David Ferreira Lima - Centro de Ciências Biológicas - Departamento - de Ciências Morfológicas - Trindade - Florianópolis - Santa Catarina - Brasil - 88040-970 - Phone: (+55) 4837219229 - e-mail: micbiz@uol.com.br

Received: November 12, 2009 - Modification: May 13, 2010 - Accepted: May 30, 2010

\section{ABSTRACT}

\begin{abstract}
Tntracanal medication in pulpectomy therapy is used between appointments with the 1 objective of reducing pain and inflammatory processes in pulp and periapical tissues. Propolis has been known as a natural antibiotic and has been subject of medical and dental research due to its therapeutic properties such as antibiotic, analgesic and antiinflammatory effects. Objective: The aim was to carry out an in vivo evaluation of the periapical tissue response to propolis paste when used as an intracanal medication in the teeth of dogs after pulpectomy. Material and Methods: 72 dog's incisors were selected for the experiment. After biomechanical preparation the root canal was filled with a corticosteroidantibiotic preparation, experimental propolis paste, non-medicament (negative control) or non-pulpectomy at all (positive control). The medications were left inside the root canal for 7,14 or 28 days. At the end of the experimental period histological sections were prepared and all laboratories processes for Harris hematoxylin and eosin staining was proceeded followed by the analysis using an optical microscope. Sections were classified according to a score representing the inflammatory events observed: the presence of polymorphonuclear neutrophils, polymorphonuclear eosinophils, lymphocytes and plasma cells, macrophages and/or giant cells, fibrous condensation and abscesses. Results: There were statistically significant differences between the tissue reactions caused by the two substances being tested, after different experimental periods, with the periapical tissue that was in contact with propolis paste exhibiting fewer inflammatory reactions in comparison to corticosteroid-antibiotic preparation. Conclusions: The low tissue responses from propolis paste suggest that this material could be considered as an option for root canal medication after pulpectomy.
\end{abstract}

Key words: Endodontics. Propolis. Pulpectomy. Dental pulp cavity.

\section{INTRODUCTION}

During endodontic treatment it may desirable or necessary to use an intracanal medication. In pulpectomy therapy intracanal medication is used between appointments with the objective of reducing pain and inflammatory processes in pulp and periapical tissues. The choice of this agent depends on its biologic characteristics: be nonirritant, control of the intensity and duration of 
inflammatory processes and infection, and have potential healing induction ${ }^{11}$. Several chemicals and therapeutic agents have been suggested as an intracanal medication: in this case, a combined corticosteroid-antibiotic could be selected 5,25

In spite of being originally designed as an otology medication, a commercial corticosteroidantibiotic preparation, Otosporin ${ }^{\circledR}$ is currently used in Dentistry as an intracanal medication due to its components: polymyxin B sulphate, neomycin sulphate, hydrocortisone and an aqueous base $\mathrm{e}^{11,16}$. This preparation reduces vasodilation, decreases liquid exudation, and also presents a direct vasoconstrictive action on small blood vessels ${ }^{10}$. Nevertheless, though this combination has many properties that are desirable as a pulpectomy intracanal medication, if it is used for prolonged periods it can reduce cellular metabolic activity and even impede or delay tissue repair ${ }^{16}$.

In relation to tissue repair, propolis has been known to be a natural antibiotic and has been the subject of medical and dental research. Propolis is a complex mixture of resinous and balsamic substances collected from plants by Apis mellifera bees, which transport them to their hives, modifying them with the addition of their own secretions, pollen and wax. Propolis contains flavonoids which are considered as the main primary biologically active component, responsible for a large proportion of its known therapeutic properties $^{17,22}$. In dentistry, propolis has been used for the treatment of aphthous ulcers, Candida albicans, acute necrotizing ulcerative gingivitis (UNUG), gingivitis and periodontitis ${ }^{9,21}$, and it has been proven to have antimicrobial activity against Streptococcus mutans ${ }^{8}$ and polymicrobial cultures collected from necrotic root canals ${ }^{28}$.

Among the properties of propolis are: analgesic action $^{6,27}$, antiviral, antifungal and antiprotozoal actions $^{1,3,7,22,30}$, immunostimulation ${ }^{24,31}$, antioxidant effects $^{30}$, antiinflammatory action ${ }^{24,27}$. All these properties led to the question whether it would be possible to use propolis as an intracanal medication in pulpectomy where there is a need for both analgesic and anti-inflammatory effects.

The objective of this study was therefore to evaluate the periapical tissue response to an experimental propolis paste when used as intracanal medication in dog's teeth after pulpectomy.

\section{MATERIAL AND METHODS}

A total of 72 incisors' root canals of 6 dogs aged 2 to 4 years were selected for the experiment. The protocol used was approved by the local Ethics Committee (CEP ULBRA: 2003-015A; CEP UPF: 276/2004).

The animals were kept under general anesthetic supplemented by infiltration of local anesthetic into the procedure area throughout the operation. Soft tissues and teeth were sterilized using alcoholiodine solution (Vico-farma, Lages, SC, Brazil).

The root canals of the 66 teeth were accessed on the buccal surface of the tooth using a diamond bur \#1012 (Metalúrgica Fava Indústria e Comércio Ltda., Franco da Rocha, SP, Brazil) at high speed with water-air cooling. After carrying out radiography on each tooth individually, the working length was established at $1 \mathrm{~mm}$ short of the radiographic root apex.

Following root canal cleaning, biomechanical preparation was carried out using a sequential manual technique. The root canal was instrumented using Flexofile ${ }^{\circledR} \mathrm{K}$ files (Dentsply, Maillefer Instruments S.A., Ballaigues, Switzerland), finishing with an instrument \#40. Canals were irrigated with $2 \mathrm{~mL}$ of solution at each instrument change, alternating between $1 \%$ sodium hypochlorite (Vico-farma) and $17 \%$ trisodium ethylenediaminetetraacetic acid (EDTA) (Vico-farma) with $\mathrm{pH}$ 7.3. Once chemomechanical preparation was complete, the apex was breached passing $2 \mathrm{~mm}$ beyond working length a file \#20. Canals were then dried with absorbent paper points \#40 (Tanari Indústria e Comércio Ltda., Paraíba do Sul, RJ, Brazil) that had been autoclaved.

The root canals were then packed with the medications to be analyzed: in each of the 6 dogs, five root canals were packed with a solution of $10 \mathrm{mg} / \mathrm{mL}$ hydrocortisone/3,400 U/ $\mathrm{mL}$ neomycin sulfate $10,000 \mathrm{U} / \mathrm{mL}$ polymyxin $\mathrm{B}$ sulfate, a corticosteroid-antibiotic preparation (Zest Farmacêutica Ltda., São Paulo, SP, Brazil) and another 5 were packed with experimental propolis paste. One root canal of each dog was packed with glycerin, which was considered as vehicle group (negative control), and another tooth did not receive any treatment, considered as the non-treated group (positive control). The choice of intracanal medication and the controls was randomized.

Corticosteroid-antibiotic preparation was stored in a clean and sterilized anesthetic tube and the solution was introduced into the canal with a Carpule syringe and a $27 \mathrm{G}$ needle set $1 \mathrm{~mm}$ short of the working length.

The experimental propolis paste was previously manipulated following the composition: $1 \%$ propolis extract, titanium dioxide, glycerin. The paste was stored in a sterilized tube and at the moment of the root canal filling it was introduced using a \#35 Lentulo spiral (Pró Dent, São Paulo, SP , Brazil), calibrated in two millimeters from the root canal working length and running at low speed in a clockwise direction. In the cases of both types of medication, insertion was stopped when reflux was 
observed at the canal entrance.

The cavity was then cleaned, filled with sterile cotton and sealed with a $2 \mathrm{~mm}$ layer of glass ionomer cement (Vidrion $\mathrm{R}^{\circledR}$ - SS White Artigos Dentários Ltda., Rio de Janeiro, RJ, Brazil), prepared in accordance with its manufacturer's instructions.

The animals spent up to 28 days with intracanal medication in place, during which time they were monitored by a veterinarian. After 7,14 or 28 days with the intracanal medication in place, the dogs were euthanized and the samples were collected.

Tissues were preserved by intravenous perfusion of $4 \%$ buffered paraformaldehyde. The maxilla and mandible were removed and postfixed in $10 \%$ neutral formaldehyde. The samples were demineralized in EDTA 4.13\% at $\mathrm{pH} 7.2$, following the process protocol for paraffin, five micrometers histological sections and hematoxylin and eosin staining. The sections were analyzed using an optical microscope (Olympus, Tokyo, Tokyo, Japan) at $\times 100, \times 200$ and $\times 400$ magnification by a single examiner, who was an experienced histologist and blind to the tested materials. The subject of analysis was the periapical region and the specimen with the greatest degree of inflammation was chosen from each sample.

The following qualitative observations were recorded: the presence of polymorphonuclear neutrophils, polymorphonuclear eosinophils, lymphocytes and plasma cells, macrophages and/ or giant cells, fibrous condensation and abscesses. Each element was attributed a numerical value according to the protocol proposed by Figueiredo, et al. ${ }^{12}$ (2001). Approximately 30 days after the original analysis of the sections, $10 \%$ of them were reanalyzed to test for intraexaminer agreement between events observed and scores awarded.

The results were tested using factorial ANOVA, followed by the Mann Whitney and Tukey's tests, all to a significance level of $5 \%$ (SPSS 12.0). Intraexaminer agreement was assessed using Kendall's W, with a 5\% significance level (SPSS 12.0).

\section{RESULTS}

The negative control slices showed a normal histological periapical tissue, without a significant inflammatory cellular event. On the other hand, positive control presented neutrophils, lymphocytes and macrophages with higher scores than negative control showing the inflammatory processes that occur after pulpectomy chemical-mechanical preparation.

Regarding to the cellular events listed for analysis, fibrous condensation was not included, once its origin was not clear in the analysis: whether due to a natural response of the periodontal ligament to the pulpectomy technique or tissue reaction to the test materials. No eosinophils were observed on any of the sections from either of the groups, being scored 1 for the analysis. Kendall's $\mathrm{W}$ showed that the intra-examiner agreement was $98.91 \%$, represented by $\mathrm{W}=0.119$.

Figure 1 illustrates variations in the number of neutrophils when analyzed with reference to the groups and experimental periods. The non-treated group had the lowest mean scores and had no variation throughout the time. Analyzing this event with relation to corticosteroid-antibiotic preparation, it is observed that there was a continuous increase in the mean scores as the experimental period elapsed, with statistically significant differences $(p=0.007)$ detected by the Tukey's test between 7 and 28 and between 14 and 28 days, which was quite similar to the vehicle group. Analyzing the mean scores for these cells for the propolis paste, there was no significant difference between the periods analyzed $(p=0.47)$. It was also possible to apply the Mann-Whitney nonparametric test in order to compare the substances at each experimental time in isolation for each of the different inflammatory events. It was not found any statistically significant differences between the tested substances for 7 days; statistically significant differences were detected for neutrophils between propolis paste and corticosteroid-antibiotic preparation, and between propolis paste and vehicle group at 14 and 28 days, with $p=0.05$ and 0.02 , consecutively, with higher

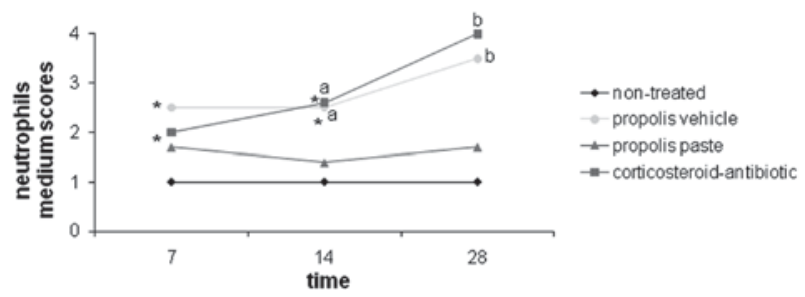

Figure 1- Progression of neutrophils medium scores of the groups over the experimental time. (a) Significant difference from propolis paste in 14 days; (b) Significant difference from propolis paste in 28 days; $\left({ }^{*}\right)$ Significant difference in the substance over time

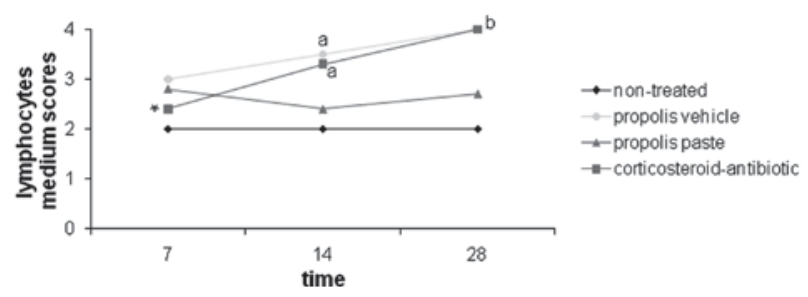

Figure 2- Progression of lymphocytes medium scores of the groups over the experimental time. (a) Significant difference from propolis paste in 14 days; (b) Significant difference from propolis paste in 28 days; $\left({ }^{*}\right)$ Significant difference in the substance over time 
scores for corticosteroid-antibiotic preparation and vehicle group; no difference between corticosteroidantibiotic preparation and vehicle group; no difference between propolis paste and non-treated group.

With relation to lymphocytes and plasma cells, illustrated in Figure 2, the non-treated group had the lowest mean scores and had no variation throughout the time. Although the test substances exhibited similar values in 7 days, by the end of the experimental period a large difference was

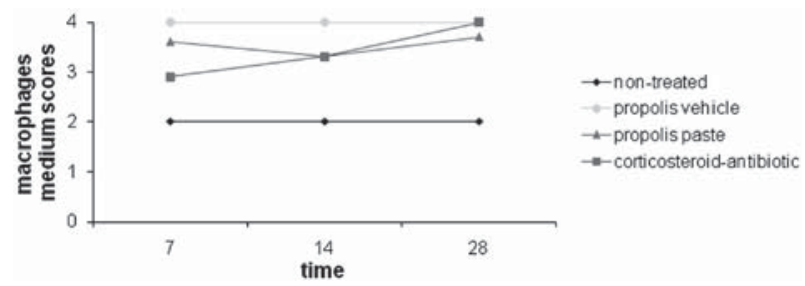

Figure 3- Progression of macrophages medium scores of the groups over the experimental time
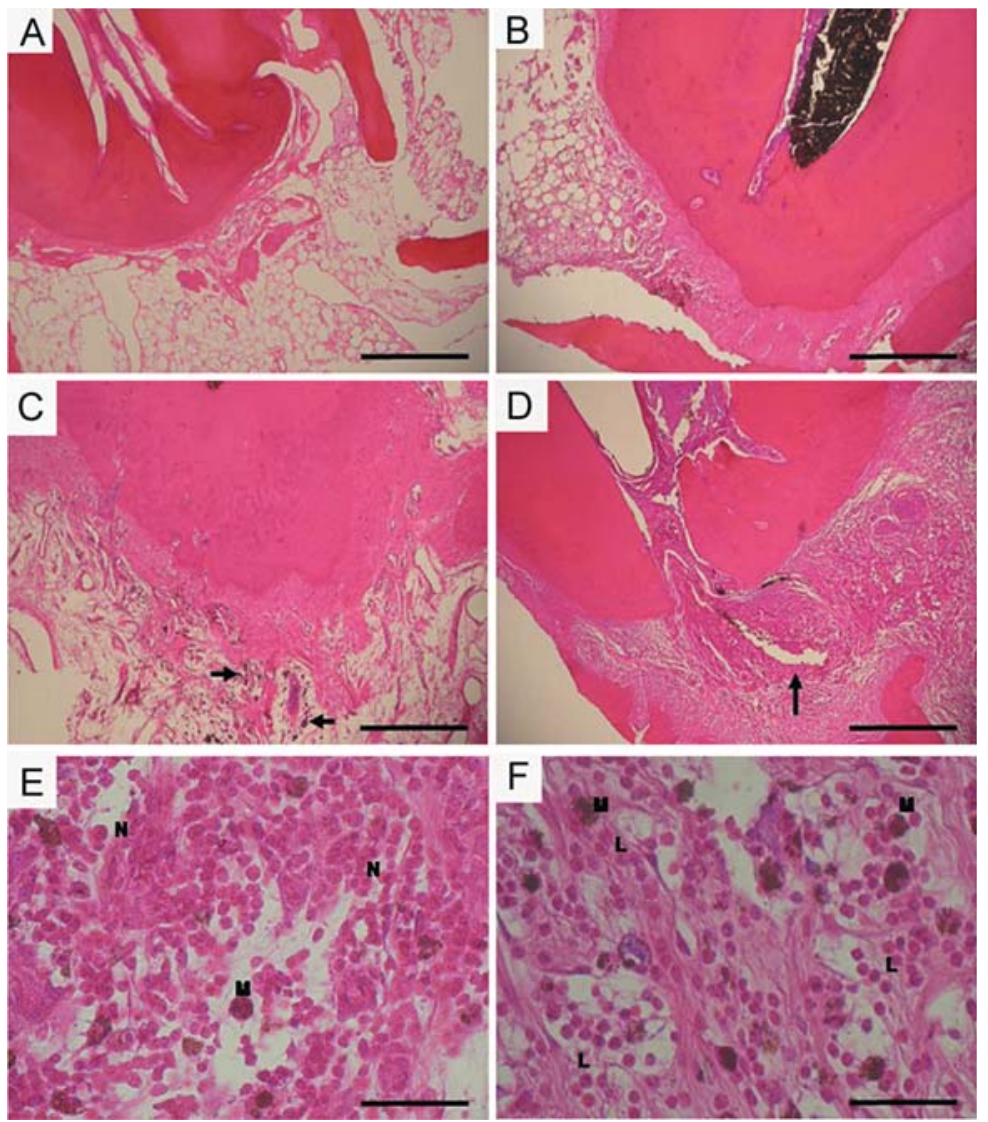

Figure 5- A- Non-treated sample - image of the periapical area of the root with a normal appearance; B- Propolis after 28 days - mild periapical inflammatory reaction; C- Propolis after 28 days - macrophages present in periapical region (arrowed); D- Otosporin 28 days - intense inflammatory reaction with abscess (arrowed); E- Otosporin 28 days - greater magnification than (D). F- Otosporin 28 days - displaced zone of abscess seen in (E). M-macrophages; N-neutrophils; L-lymphoplasmacytic infiltrate. Bars: A-E $200 \mu \mathrm{m} ; \mathrm{F}-\mathrm{G} 50 \mu \mathrm{m}$ 
no statiscally significant differences between the tested substances for 7 days. Significant difference between corticosteroid-antibiotic preparation and propolis paste, and between propolis paste and vehicle group at 14 and 28 days, with $p=0.01$ and 0.02 , consecutively, with higher scores for corticosteroid-antibiotic preparation and vehicle group; no difference between corticosteroidantibiotic preparation and vehicle group; no difference between propolis paste and non-treated group.

The non-treated group had the lowest mean scores and had no variation throughout the time for macrophages and giant cells. Analysis of the mean scores between the tendencies of cellular expression for vehicle group, propolis paste and corticosteroid-antibiotic preparation showed that these events were constantly present in the tissues analyzed, with no significant differences between them. There were no significant differences when each of the experimental groups was analyzed alone with relation to the variable time $(p>0.05)$ (Figure 3).

Figure 4 illustrates the mean scores for abscesses for the tested groups. In 7 days abscesses were practically absent for all groups. The non-treated group and the propolis paste group did not exhibit any significant difference over time ( $p>0.05)$. However, as time passed, there was a drastic increase in the corticosteroid-antibiotic preparation and vehicle group with statistically significant differences $(p<0.05)$, detected by the Tukey test, between 7 and 14 and between 7 and 28 days. For this event, corticosteroid-antibiotic preparation and vehicle group had the higher scores when compared with propolis paste and non-treated group at 28 days, with a significant difference $(p<0.05)$ as detected by Mann-Whitney nonparametric test; there was no statiscally significant differences between the substances for 7 and 14 days.

Figure 5 shows representative images of samples tested after 28 days in contact with periapical tissues. Figure $5 \mathrm{~A}$ is a representative image of the non-treated group: normal periapical tissue, with no inflammatory cells. In the corticosteroidantibiotic preparation (Figure 5E-F), it is possible to observe the presence of intense inflammation after 28 days, whereas there is merely mild periapical inflammation after exposure to the propolis paste (Figure 5B-D).

\section{DISCUSSION}

During pulpectomy the pulp removal and chemical-mechanical preparation will lead the periapical tissues into an acute inflammatory process $^{5,25}$, which explains the result of the vehicle group in this experiment. As it is known by the literature, the main cellular events to be taken into consideration when attempting to observe an initial inflammatory response in tissues are neutrophils and the presence of abscesses. When neutrophils are present it signify that an acute process is occurring, during which these cells are constantly recruited to contain inflammation. These are the first cells to migrate from blood vessels and to reach the site of aggression. Nevertheless, if the aggression is intense and neutrophils are unable to contain it rapidly, abscesses may form from a buildup of dead neutrophils, tissue liquids and abnormal material, creating pus ${ }^{18}$.

Corticosteroid based medicaments acts on the synthesis of lipocortin and vasocortin, inhibiting the formation of edema and A2 phospholipasis enzymes, once inhibiting this enzyme, membrane phospholipids cannot be converted into arachidonic acid. Therefore, the cyclooxygenase and lypooxygenase are blocked 20,33 . Corticosteroid preparation also acts on histamine, heparin, and bradicinin, which are important chemical mediators in the initial phases of acute inflammation ${ }^{10,29}$. Propolis-based medicaments contains flavonoids which are considered as the main primary biologically active component, responsible for a large proportion of its known therapeutic properties ${ }^{17,22}$. The flavonoids interfere in the arachidonic acid metabolism and so interfere in the cyclooxygenase and lypooxygenase synthesis. Some of the substances derivate in this cascade are the prostaglandins, thromboxane and leukotriene which are important to keep the integrity of the inflammatory reaction ${ }^{13,14}$. Therefore, it is expected that the use of corticosteroid preparations and propolis-based medicaments cause changes in the inflammatory response in the tissue as it was observed in this study and discussed in the following sentences.

When the results were analyzed, corticosteroidantibiotic preparation had high scores for the presence of neutrophils and abscesses, primarily from 14 days onwards. The intense neutrophil infiltrate, which was continuously present and had not receded by 28 days, demonstrates the severity of the inflammatory response to corticosteroidantibiotic preparation. It was already discussed in the literature that if this medication is left in contact with remaining apical tissues for longer periods the tissue response in this region can become completely compromised ${ }^{16}$. On the other hand, it could be possible that after 28 days, no more corticosteroid-antibiotic should be in the root canal and this fact could explain why corticosteroidantibiotic preparation had the same inflammatory reaction in 28 days as the vehicle group (glycerin), which is considered an inert substance.

In contrast, the scores for neutrophils and 
abscesses in the propolis paste group illustrate a tissue reaction that is more favorable to the repair process, since their means were low and remained constant as the experimental period elapsed, quite similar to the non-treated group. This corroborates studies by Bretz, et al. ${ }^{4}$ (1998), Al-Shaher, et al. ${ }^{2}$ (2004) and Silva, et al. ${ }^{32}$ (2004), which have demonstrated that administering propolis-based substances leads to tissues exhibiting normal reorganization without increased vascular or cellular events, maintaining low levels of inflammation.

It is important to emphasize that, in this study, after 7 days of experiment, all tested substance had the same behavior: low levels of inflammatory cells. The differences between the two substances were primarily observed after the 14 and 28day experimental periods, with the scores for neutrophils and abscesses being similar in 7 days. This result supports the indication for using corticosteroid-based medications for periods no longer than 7 days $^{16}$.

With relation to the presence of lymphocytes and plasma cells, these events characterize the presence of a chronic process. The mean values for the corticosteroid-antibiotic preparation used at 14 and 28 days appear to be more worrying since they indicate that there was intense lymphoplasmacytic infiltrate, which did not recede as the experimental period elapsed.

Regarding the absence of eosinophils, their presence is intimately related with allergic processes and thus, despite the literature describing cases of allergy to propolis ${ }^{15,19,28}$, at least in this study, this effect was not observed.

Analyzing cellular events as a whole, it was observed that in the corticosteroidantibiotic preparation group, they increased as the experimental period elapsed, indicating a deterioration of the inflammatory process. This was not the case with the propolis paste, since no significant difference between the events analyzed occurred during the experimental period.

These observations have been confirmed in a study by Silva, et al. ${ }^{32}$ (2004), where it was demonstrated that propolis is more effective at reducing acute inflammatory processes than corticosteroid-antibiotic preparation. These findings confirm the anti-inflammatory activity mentioned in earlier published studies ${ }^{23,27}$.

Based on the obtained results, this study shows that propolis paste is a viable alternative for intracanal medication in cases of pulp or periapical inflammatory processes. Length of time in contact with these tissues is a critical factor and, if an endodontic treatment cannot be completed in a single session, using corticosteroid-antibiotic preparation for a period of more than 7 days may worsen the inflammatory process. In this experiment, propolis paste in contact with periapical tissues after pulpectomy did not appear to be a problem. Furthermore, the propolis paste was more effective at controlling the inflammatory response over the 28-day experimental period.

Here it was demonstrated that the experimental propolis paste had the lowest value of inflammatory cells events, with mean scores similar to the negative control group. This indicates that the propolis paste could be considered as an intracanal medication possibility. However, it is important to emphasize that this is part of a primary study with the experimental propolis paste. Basic science and clinical experimental should be performed to better know its properties and possible use in Endodontic treatments.

\section{CONCLUSION}

Within the context of the methodology proposed and results observed, it is possible to conclude that propolis paste caused a periapical mild inflammatory response with no variation throughout the experimental period when compared with corticosteroid-antibiotic preparation; corticosteroidantibiotic preparation caused an increasing degree of inflammatory response that was directly related to the length of time, being most severe at 28 days.

\section{REFERENCES}

1- Abdel-Fattah NS, Nada OH. Effect of propolis versus metronidazole and their combined use in treatment of acute experimental giardiasis. J Egypt Soc Parasitol. 2007;37:691-710. 2- Al-Shaher A, Wallace J, Agarwal S, Bretz W, Baugh D. Effect of propolis on human fibroblast from the pulp and periodontal ligament. J Endod. 2004;30:359-61.

3- Amoros M, Lurton E, Boustie J, Girre L, Sauvager F, Cormier M. Comparison of the anti-herpes simplex virus activities of propolis and 3-methyl-but-2-enyl caffeate. J Nat Prod. 1994;57:644-7. 4- Bretz WA, Chiego DJ Jr, Marcucci MC, Cunha I, Custódio A, Schneider LG. Preliminary report on the effects of propolis on wound healing in the dental pulp. Z Naturforsch C. 1998;53:10458.

5- Campos RO, Paulino N, Silva CH, Scremin A, Calixto JB. Antihyperalgesic effect of an ethanolic extract of propolis in mice and rats. J Pharm Pharmacol. 1998;50:1187-93.

6- Chong BS, Pitt Ford TR. The role of intracanal medication in root canal treatment. Int Endod J. 1992;25:97-106.

7- Dobrowolski JW, Vohora SB, Sharma K, Shah SA, Naqvi SA, Dandiya PC. Antibacterial, antifungal, antiamoebic, antiinflammatory and antipyretic studies on propolis bee products. J Ethnopharmacol. 1991;35:77-82.

8- Duailibe SA, Gonçalves AG, Ahid FJ. Effect of a propolis extract on Streptococcus mutans counts in vivo. J Appl Oral Sci. 2007; 15:420-3.

9- Duarte s, Koo H, Bowen WH, Hayacibara MF, Cury JA, Ikegaki $M$, et al. Effect of a novel type of propolis an its chemical fractions on glucosyltransferases and on growth and adherence of mutans streptococci. Biol Pharm Bull. 2003;26:527-31.

10- Fachin EVF, Scarparo RK, Pezzi AP, Luisi SB, Sant'ana M Filho. Effect of betamethasone on the pulp after topical application to the dentin of rat teeth: vascular aspects of the inflammation. J Appl Oral Sci. 2009;17:335-9. 
11- Fava LRG. Human pulpectomy: incidence of postoperative pain using two different intracanal dressing. Int Endod J. 1992;25:25760 .

12- Figueiredo JAP, Pesce HF, Gioso MA, Figueiredo MA. The histological effects of four endodontics sealers implanted in the oral mucosa: submucous injection versus implant in polyethylene tubes. Int Endod J. 2001;34:377-85.

13- Formica JV, Regelson W. Review of the biology of Quercetin and related bioflavonoids. Food Chem Toxicol. 1995;33:1061-80. 14- Harborne JB, Williams CA. Advances in flavonoid research since 1992. Phytochemistry. 2000;55:481-504.

15- Hausen BM, Wollenweber E, Senff H, Post B. Propolis allergy. (I). Origin, properties, usage and literature review. Contact Dermatitis. 1987; 17:163-70.

16- Holland R, Otoboni-Filho JA, Souza V, Nery MJ, Bernabé PFE, Dezan E Jr. Calcium hydroxide and corticosteroid-antibiotic association as dressings in cases of biopulpectomy. A comparative study in dogs' teeth. Braz Dent J. 1998;9:67-76.

17- Koo H, Gomes BPFA, Rosalen PL, Ambrosano GMB, Park YK, Cury JA. In vitro antimicrobial activity of propolis and Arnica montana against oral pathogens. Arch Oral Biol. 2000;45:141-8. 18- Kumar V, Cotran RS, Robbins SL. Robbins basic pathology. Philadelphia: Saunders; 2003.

19- Machácková J. The incidence of allergy to propolis in 605 consecutive patients patch tested in Prague. Contact Dermatitis. 1988;18:210-2.

20- Magro Filho O, Carvalho ACP. Application of propolis to dental sockets and skin wounds. J Nihon Univ Sch Dent. 1990;32:4-13. 21- Manchikanti L. Role of neuraxial steroids in interventional pain management. Pain Physician. 2002;5:182-99.

22- Marcucci MC. Propolis: chemical composition, biological properties and therapeutic activity. Apidologie. 1995;26:83-99.
23- Naito Y, Yasumuro M, Kondou K, Ohara N. Antiinflammatory effect of topically applied propolis extract in carrageenan-induced rat hind paw edema. Phytother Res. 2007;21:452-6.

24- Neychev H, Dimov V, Vuleva V, Shirova L, Slavcheva E, Gegova $\mathrm{G}$, et al. Immunomodulatory action of propolis. II. Effect of watersoluble fraction on influenza infection in mice. Acta Microbiol Bulg. 1988;23:58-62.

25- Nobuhara WK, Carnes DL, Gilles JA. Anti-inflammatory effects of dexamethasone on the periapical tissues following endodontic overinstrumentation. J Endod. 1993;19:501-7.

26- Paulino N, Abreu SR, Uto Y, Koyama D, Nagasawa $\mathrm{H}$, Hori H, et al. Anti-inflammatory effects of a bioavailable compound, Artepillin C, in Brazilian propolis. Eur J Pharmacol. 2008;587:296-301. 27- Paulino N, Teixeira C, Martins R, Scremin A, Dirsch VM, Vollmar $A M$, et al. Evaluation of the analgesic and anti-inflammatory effects of a Brazilian green propolis. Planta Med. 2006;72:899-906.

28- Ratón JA, Aguirre A, Díaz-Pérez JL. Contact dermatitis to propolis. Contact Dermatitis. 1990;22:183-4.

29- Rezende GPSR, Costa LRRS, Pimenta FC, Baroni DA. In vitro antimicrobial activity of endodontic pastes with propolis extracts and calcium hydroxide: a preliminary study. Braz Dent J. 2008;19:301-5.

30- Russo A, Longo R, Vanella A. Antioxidant activity of propolis: role of caffeic acid phenethyl ester and galangin. Fitoterapia. 2002;73(Suppl 1):21-9.

31- Sforcin JM. Propolis and the immune system: a review. J Ethnopharmacol. 2007;113:1-14.

32- Silva FB, Almeida JM, Sousa SM. Natural medicaments in endodontics - a comparative study of the anti-inflammatory action. Braz Oral Res. 2004;18:174-9.

33- Trowbridge HO, Emiling RC. Inflammation: a review of the process. Chicago: Quintessence; 1997. 